\title{
Role of once-daily glycopyrronium bromide (NVA237) in the management of COPD
}

This article was published in the following Dove Press journal:

Therapeutics and Clinical Risk Management

17 August 2013

Number of times this article has been viewed

\section{Anthony D'Urzo}

Department of Family and Community Medicine, University of Toronto, Toronto, ON, Canada
Correspondence: Anthony D'Urzo Department of Family and Community Medicine, University of Toronto, 1670 Dufferin Street, Suite 107, Toronto, ON, M6H3M2 Canada $\mathrm{Tel}+\mathrm{I} 4166529336$

Fax + 4166520218

Email tonydrzo@sympatico.ca
Abstract: Progressive airflow limitation is a hallmark feature of chronic obstructive pulmonary disease (COPD) that ultimately leads to breathlessness, impaired quality of life, and reduced exercise capacity. Pharmacotherapy is used in patients with COPD to prevent and control symptoms, reduce both the frequency and severity of exacerbations, improve health status, and increase exercise tolerance. These strategies are intended to address management issues which promote both current disease control and a reduction in the risk of disease deterioration in the future. At the present time, long-acting $\beta_{2}$-agonists (LABAs) and long-acting muscarinic antagonists (LAMAs) are available for maintenance therapy in patients with persistent symptoms. Tiotropium was the first LAMA to be approved for management of COPD, and many studies have described its beneficial effects on multiple clinically relevant outcomes. Glycopyrronium bromide (NVA237), a new LAMA, has been developed and received regulatory approval for management of COPD in a number of countries around the world. Results from pivotal Phase III trials suggest that NVA237 is safe and well tolerated in patients with moderate to severe COPD, and provides rapid and sustained improvements in lung function. Further, these changes are associated with statistically and clinically meaningful improvements in dyspnea, health-related quality of life, and exercise tolerance. Treatment with NVA237 also results in a significant reduction in risk of exacerbations and the need for rescue medication, and has been comparable with tiotropium with respect to safety and efficacy outcomes. Finally, emerging data indicate that NVA237 is efficacious both as monotherapy and in combination with indacaterol.

Keywords: glycopyrronium bromide, NVA237, chronic obstructive pulmonary disease, inhaled long-acting bronchodilators

\section{Introduction}

Progressive limitation in airflow is a hallmark feature of chronic obstructive pulmonary disease (COPD) that ultimately leads to breathlessness, impaired quality of life, and reduced exercise capacity. ${ }^{1,2}$ Unlike other common chronic conditions, COPD continues to be a leading cause of morbidity and mortality worldwide. ${ }^{1,2}$

Pharmacotherapy is used in patients with COPD to prevent and control symptoms, reduce the frequency and severity of exacerbations, improve health status, and increase exercise tolerance. ${ }^{1}$ These strategies are intended to address management issues which promote both current disease control and a reduction in risk of deterioration of the disease in the future. ${ }^{1}$ Given that increased airway resistance contributes to the symptoms of COPD, treatment to a large extent relies on use of bronchodilators which influence the activity of beta ${ }_{2}$ and muscarinic receptors in the airway. ${ }^{1}$ At the present time, long-acting $\beta_{2}$-agonists (LABAs) and long-acting muscarinic 
antagonists (LAMAs) are available for maintenance therapy in patients with persistent symptoms. Tiotropium was the first LAMA to be approved for the management of COPD, and many studies have described its beneficial effects on many clinically relevant outcomes. ${ }^{1}$ More recently, the Seebri ${ }^{\circledR}$ Breezhaler ${ }^{\circledR}$ (glycopyrronium bromide) a new, once daily, LAMA developed as NVA237 by Novartis Pharma AG, Basel, Switzerland, has received regulatory approval for management of COPD in a number of countries around the world. ${ }^{3}$ Aclidinium bromide is a twice-daily LAMA that has also been approved recently in the European Union and in the US for the treatment of COPD. ${ }^{4}$ This review focuses on the role of the novel LAMA, NVA237, in the management of COPD. The clinical evidence supporting the benefits of NVA237 focus on data from pivotal Phase III studies. The clinical data are presented in keeping with the Global Initiative for Chronic Obstructive Lung Disease 2011 recommendations, ${ }^{1}$ with a view to providing pragmatic strategies that can be adopted in both primary and secondary care environments. The emerging utility of NVA237 in management of COPD, including its role in combination with the LABA indacaterol, is also reviewed to provide an evolving perspective on how it may be incorporated into future guidelines on COPD management.

\section{Mechanism and onset of action}

Anticholinergic bronchodilators such as ipratropium and oxitropium were originally introduced as short-acting preparations and more recently as a longer-acting formulation (tiotropium). ${ }^{5}$ These older compounds have played an important role in the management of COPD for almost 25 years. The effectiveness of these therapies stems in part from the fact that vagally mediated bronchoconstriction represents a significant reversible component of airflow obstruction in patients with COPD. The competition with acetylcholine for binding to the muscarinic (M3) receptor on bronchial smooth muscle cells, thereby abolishing bronchomotor tone, is a central function of antimuscarinic agents. ${ }^{5}$ Newer bronchodilator therapies, with a longer duration of action, appear to be more efficacious than shorteracting agents for improving relevant clinical outcomes in patients with COPD of varying disease severity, in large part because prolonged stenting of the airways allows for more complete lung emptying over time. ${ }^{1}$

NVA237 (glycopyrronium bromide) is a new LAMA that acts as a competitive antagonist by binding to muscarinic receptors in bronchial smooth muscle, resulting in inhibition of acetylcholine-induced bronchoconstriction. It appears that
NVA237 can to bind to all five subtypes of the muscarinic receptor $\left(\mathrm{M}_{1}-\mathrm{M}_{5}\right){ }^{6}$ It is the $\mathrm{M}_{3}$ receptor located on airway smooth muscle that is primarily involved in smooth muscle contraction. It is important to note that blockade of $\mathrm{M}_{2}$ receptors is associated with attenuation of the feedback inhibition of acetylcholine production, an activity that may reduce the bronchodilating effects of an antimuscarinic agent. Further, if cardiac $\mathrm{M}_{2}$ receptors are blocked, this may result in an increase in heart rate. ${ }^{6}$ Therefore, the ideal antimuscarinic agent for use in COPD should have features that promote high affinity for $M_{1}$ and $M_{3}$ receptors and low affinity for $M_{2}$ receptors. Tiotropium bromide and NVA237 share similar features, which include a higher selectivity for $\mathrm{M}_{3}$ receptors than for $\mathrm{M}_{2}$ receptors. $^{6-8}$ Further, like tiotropium bromide and aclidinium bromide, NVA237 dissociates more slowly from the $M_{3}$ receptor than from the $M_{2}$ receptor. $^{6-8}$

\section{Clinical considerations}

LAMAs and LABAs are recognized in the Global Initiative for Chronic Obstructive Lung Disease and the National Institute for Health and Clinical Excellence guidelines ${ }^{9,10}$ as first-line maintenance therapies for patients with moderateto-severe COPD (Figure 1). Numerous studies have reported that both tiotropium and LABAs are efficacious for improving lung function and quality of life, and for reducing acute exacerbations and hospitalizations in patients with moderateto-severe COPD. ${ }^{10,11-16}$ At present, it is not entirely clear as to whether patients should be initiated on monotherapy with either a LAMA or a LABA or a combination of both. This uncertainty relates in part to the absence of long-term studies comparing these different approaches in patients with varying clinical features and levels of pulmonary impairment.

Until recently, tiotropium was the only LAMA approved for the management of COPD. Numerous studies have established that it is a safe and effective therapy and that it improves a range of important clinical outcomes. For example, compared with placebo, tiotropium is associated with superior bronchodilation, ${ }^{17}$ increased inspiratory capacity, ${ }^{18,19}$ increased exercise capacity, ${ }^{18,20,21}$ reduced dyspnea, ${ }^{17,22}$ improved health status, ${ }^{17,22}$ and reduced exacerbations. ${ }^{17,23}$ In patients with moderate-to-severe COPD, the newer oncedaily agent, NVA237, has been shown to provide sustained 24-hour bronchodilation, to have a rapid onset of action, and to be safe and well tolerated. ${ }^{6-8}$ All doses of NVA237 evaluated (up to $200 \mu \mathrm{g}$ ) appear to be well tolerated, with doses of $50 \mu \mathrm{g}$ or $100 \mu \mathrm{g}$ once daily having greater efficacy than lower doses. ${ }^{24-26}$ The recent approval of NVA237 for use in the management of COPD offers clinicians another 


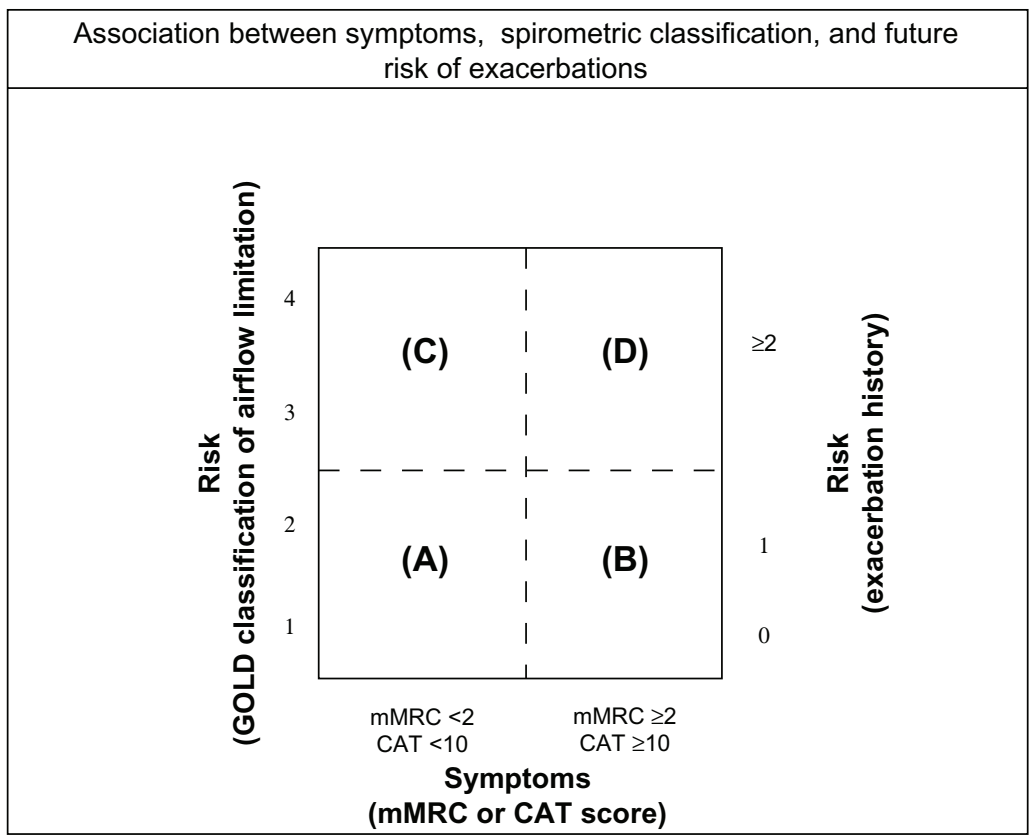

Patient group A - low risk, less symptoms

Typically GOLD 1 or GOLD 2 (mild or moderate airflow limitation)

and/or $\leq 1$ exacerbation per year and mMRC grade $<2$ or CAT score $<10$

Patient group B - low risk, more symptoms

Typically GOLD 1 or GOLD 2 (mild or moderate airflow limitation) and/or $\leq 1$ exacerbation per year and $\mathrm{mMRC} \geq 2$ or CAT score $\geq 10$

\section{Patient group C - high risk, less symptoms}

Typically GOLD 3 or GOLD 4 (severe or very severe airflow limitation) and/or $\geq 2$ exacerbations per year and mMRC grade $<2$ or CAT score $<10$

\section{Patient group D - high risk, more symptoms}

Typically GOLD 3 or GOLD 4 (severe or very severe airflow limitation) and/or $\geq 2$ exacerbations per year and mMRC grade $\geq 2$ or CAT score $\geq 10$

Figure I Global strategy for diagnosis, management and prevention of COPD: combined assessment of COPD.

Note: Reproduced with permission from Global initiative for Obstructive Lung Disease. Global strategy for the diagnosis, management, and prevention of chronic obstructive pulmonary disease; Revised 20II. Copyright (C) 20II.'

Abbreviations: GOLD, Global initiative for Obstructive Lung Disease; COPD, chronic obstructive pulmonary disease; mMRC, modified Medical Research Council; CAT, COPD Assessment Test.

therapeutic option, and warrants a thorough review of the available literature outlining its clinical usefulness and its anticipated positioning in current guidelines.

\section{Pivotal phase III trials GLOW I}

\section{Study design and methods}

In GLOW 1 (the Glycopyrronium bromide in COPD airways clinical study 1), patients had to complete a seven-day prescreening period followed by a 14-day run-in period in a double-blind, placebo-controlled manner. ${ }^{27}$ Subjects who met the eligibility criteria were randomized in a 2:1 ratio to 26 weeks of treatment with either NVA237 $50 \mu \mathrm{g}$ or placebo once daily. Medication was administered via a single-dose dry-powder inhaler with low internal resistance (the Breezhaler device). Study outcomes included the efficacy, safety, and tolerability of once-daily NVA23750 $\mu \mathrm{g}$ compared with placebo in patients with moderate to severe COPD. In total, 822 patients were randomized to NVA237 $(\mathrm{n}=552)$ or placebo $(\mathrm{n}=270)$.

Trough forced expiratory volume in one second $\left(\mathrm{FEV}_{1}\right)$ at week 12 was the primary outcome. Enrolled patients included men and women $>40$ years of age, with a smoking history of $\geq 10$ pack-years, a diagnosis of moderate to severe stable 
COPD,${ }^{9}$ a post-bronchodilator $\mathrm{FEV}_{1} \geq 30 \%$ and $<80 \%$ of the predicted normal, and post-bronchodilator $\mathrm{FEV}_{1} /$ forced vital capacity $<0.70$.

Secondary outcome measures included assessment of breathlessness using the transition dyspnea index and healthrelated quality of life data captured using the St George's Respiratory Questionnaire at week 26. Mean time to first moderate to severe COPD exacerbation and mean daily use of rescue medication over 26 weeks were also examined. Other outcome measures included trough $\mathrm{FEV}_{1}$ at the end of day 1 and at week 26. Finally, measurements of serial spirometry at various time points, including inspiratory capacity, were also evaluated.

Inhaled corticosteroids (ICS), intranasal corticosteroids, and $\mathrm{H} 1$ antagonists were allowed during the study period only if patients had been stabilized on a recommended and constant dose prior to study entry. The washout period for long-acting bronchodilator therapy prior to the run-in period was 48 hours for LABAs-ICS combinations and seven days for tiotropium. Patients were encouraged to use rescue medication on an "as-needed" basis. Patients using fixed-dose LABAs-ICS combination products were switched to an equivalent dose of ICS during the run-in phase and throughout the study period. During the screening period, the dose of ICS had to remain stable. Patients using ICS prior to screening continued on their prestudy regimen for the duration of the study. Salbutamol inhalers were provided to all patients for use as rescue medication during the study.

\section{Efficacy data}

Trough FEV , was significantly higher at week 12 in patients receiving NVA237 (least squares mean \pm standard error,
$1.408 \pm 0.0105 \mathrm{~L})$, versus placebo $(1.301 \pm 0.0137 \mathrm{~L}$, treatment difference $108 \pm 14.8 \mathrm{~mL}, P<0.001$, Figure 2). Differences in trough $\mathrm{FEV}_{1}$ were observed as early as the end of day 1 and were maintained through week 26 . Treatment with NVA237 was associated with significant improvements in $\mathrm{FEV}_{1}$ throughout the 24-hour periods on day 1 and at weeks 12 and 26 compared with placebo. The superiority of NVA237 in improving $\mathrm{FEV}_{1}$ compared with placebo was observed at all other visits and study time points. In a subpopulation of patients who underwent measurements of serial spirometry throughout the 24-hour periods on day 1 and at weeks 12 and 26, treatment with NVA237 resulted in significant improvement in $\mathrm{FEV}_{1}$ compared with placebo. Measurements of inspiratory capacity were obtained to evaluate the influence of NVA237 on lung hyperinflation at rest. In patients receiving NVA237, inspiratory capacity was significantly increased at all time points on day 1 and at weeks 12 and 26 (all $P<0.001$, Table 1) compared with placebo. Mean differences in inspiratory capacity for NVA237 versus placebo were $104 \mathrm{~mL}, 97 \mathrm{~mL}$, and $113 \mathrm{~mL}$ (all $P<0.001$ ) by the end of day 1 , week 12 , and week 26 , respectively.

\section{Dyspnea and quality of life data}

Significant treatment differences in focal scores for the transition dyspnea index $(1.04, P<0.001)$ and total scores on the St George's Respiratory Questionnaire $(-2.81, P=0.004)$ in favor of NVA237 were observed at week 26. A statistically significant reduction in the risk of first moderate to severe COPD exacerbation of $31 \%(P=0.023)$ was observed in the patients receiving NVA237 despite a relatively low baseline exacerbation burden in the overall population at study entry. Administration of NVA237 was also associated with a reduction

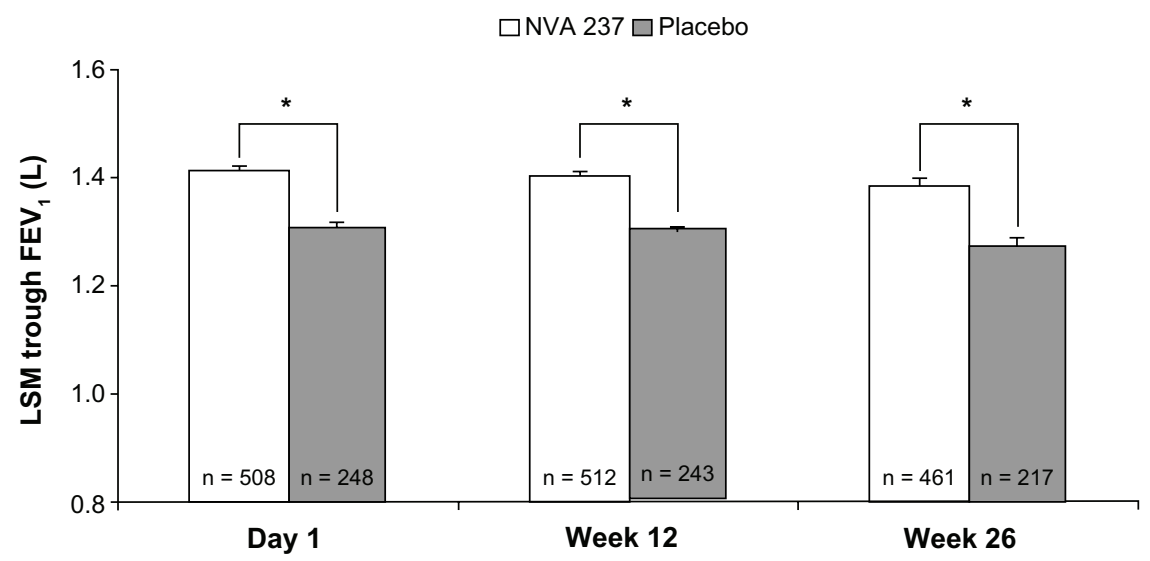

Figure 2 Trough FEV, on Day I and at Weeks I2 and 26.

Notes: Data are least squares means + standard error; $* P<0.00 \mathrm{I}$; Treatment differences: Day I = $105 \pm 10.9 \mathrm{~mL} ; \mathrm{Week} 12=108 \pm 14.8 \mathrm{~mL}$; Week $26=113 \pm 16.5 \mathrm{~mL}$. Reproduced from D'Urzo A, Ferguson GT, van Noord JA, et al. Efficacy and safety of once-daily NVA237 in patients with moderate-to-severe COPD: the GLOWI trial. Respir Res. 2011;12:156.27

Abbreviations: $\mathrm{FEV}_{1}$, forced expiratory volume in one second; LSM, least square mean. 
Table I Inspiratory capacity on day I and at weeks I 2 and 26 in the FAS population

\begin{tabular}{|c|c|c|c|c|}
\hline & \multicolumn{3}{|c|}{ Inspiratory capacity, L } & \multirow[t]{2}{*}{$P$-value } \\
\hline & $\begin{array}{l}\text { NVA237 } 50 \mu \mathrm{g} \\
(\mathrm{n}=534)\end{array}$ & $\begin{array}{l}\text { Placebo } \\
(n=260)\end{array}$ & Difference & \\
\hline \multicolumn{5}{|l|}{ Day I } \\
\hline $25 \mathrm{~min}$ & $2.110 \pm 0.0148$ & $1.930 \pm 0.0194$ & $0.181 \pm 0.0212$ & $<0.001$ \\
\hline I h 55 min & $2.166 \pm 0.0157$ & $1.978 \pm 0.0210$ & $0.182 \pm 0.0230$ & $<0.001$ \\
\hline 3 h 55 min & $2.139 \pm 0.0164$ & $1.970 \pm 0.0217$ & $0.160 \pm 0.0232$ & $<0.001$ \\
\hline $23 \mathrm{~h} 40 \mathrm{~min}$ & $2.019 \pm 0.0168$ & $1.915 \pm 0.0222$ & $0.101 \pm 0.0239$ & $<0.001$ \\
\hline \multicolumn{5}{|l|}{ Week 12} \\
\hline$-20 \min$ & $1.967 \pm 0.0221$ & $\mathrm{I} .883 \pm 0.028 \mathrm{I}$ & $0.08 \mathrm{I} \pm 0.0286$ & 0.003 \\
\hline $25 \mathrm{~min}$ & $2.048 \pm 0.0216$ & $1.000 \pm 0.0274$ & $0.148 \pm 0.0278$ & $<0.001$ \\
\hline I h $55 \mathrm{~min}$ & $2.103 \pm 0.0232$ & $1.023 \pm 0.0297$ & $0.180 \pm 0.0305$ & $<0.001$ \\
\hline 3 h 55 min & $2.040 \pm 0.0218$ & $1.808 \pm 0.0285$ & $0.142 \pm 0.0300$ & $<0.001$ \\
\hline $23 \mathrm{~h} 40 \mathrm{~min}$ & $2.000 \pm 0.0212$ & $1.912 \pm 0.0282$ & $0.007 \pm 0.0296$ & $<0.001$ \\
\hline \multicolumn{5}{|l|}{ Week 26} \\
\hline$-20 \min$ & $1.988 \pm 0.0202$ & $1.879 \pm 0.0267$ & $0.109 \pm 0.0281$ & $<0.001$ \\
\hline $25 \min$ & $2.055 \pm 0.0205$ & $1.905 \pm 0.0272$ & $0.150 \pm 0.0285$ & $<0.001$ \\
\hline I h $55 \mathrm{~min}$ & $2.107 \pm 0.0214$ & $1.929 \pm 0.0288$ & $0.178 \pm 0.0309$ & $<0.001$ \\
\hline $3 \mathrm{~h} 55 \mathrm{~min}$ & $2.080 \pm 0.0206$ & $1.915 \pm 0.0283$ & $0.165 \pm 0.0304$ & $<0.001$ \\
\hline $23 \mathrm{~h} 40 \mathrm{~min}$ & $1.997 \pm 0.0192$ & $1.884 \pm 0.0257$ & $0.113 \pm 0.0275$ & $<0.001$ \\
\hline
\end{tabular}

Notes: Values are least squares means \pm standard errors. Reproduced from D'Urzo A, Ferguson GT, van Noord JA, et al. Efficacy and safety of once-daily NVA237 in patients with moderate-to-severe COPD: the GLOWI trial. Respir Res. 201 I;12:156. ${ }^{27}$

Abbreviation: FAS, full analysis set.

in use of rescue medication by 0.46 puffs per day $(P=0.005)$ versus placebo.

\section{Safety data}

The incidence of adverse events among patients receiving NVA237 was $57.5 \%$ compared with $65.2 \%$ in the placebo group. The higher frequency of adverse events in the placebo group was attributed to worsening of COPD. Other adverse events, including gastrointestinal disturbances, urination difficulty, urinary retention, and dry mouth occurred at low frequencies in both the NVA237 and placebo groups. Serious adverse events and discontinuations due to adverse events tended to be less frequent in patients receiving NVA237 than in those receiving placebo. Excluding serious worsening of COPD, which was less frequent in the NVA237 group, a similar percentage of serious adverse events were observed in the NVA237 and placebo groups.

\section{Summary}

The results of GLOW 1 suggest that NVA237 is safe and well tolerated in patients with moderate to severe COPD, providing rapid improvements in lung function that are sustained over time. Further, these latter changes were also associated with statistically significant and clinically meaningful improvements in dyspnea and health-related quality of life. Finally, treatment with NVA237 resulted in a significant reduction in risk of exacerbations and need for rescue medication.

\section{GLOW 2}

\section{Study design and methods}

In the multicenter, placebo-controlled, double-blind, parallel-group GLOW 2 (The GLycopyrronium bromide in COPD airWays clinical study 2), patients who fulfilled the inclusion criteria were randomized in a $2: 1: 1$ ratio to receive NVA237 $50 \mathrm{mg}$, placebo, or open-label tiotropium $18 \mathrm{mg}$ for 52 weeks. ${ }^{28}$ NVA237 $50 \mathrm{mg}$ and placebo were delivered using a single-dose dry-powder inhaler with low internal resistance (the Breezhaler device). Open-label tiotropium $18 \mathrm{mg}$ was delivered via the HandiHaler ${ }^{\circledR}$ device (Boehringer Ingelheim, Ingelheim, Germany). All study treatments were administered in the morning between 8 am and 11 am for the duration of the 52-week study period following appropriate washout and run-in phases. Use of concomitant medications was similar to that described in the GLOW 1 study. ${ }^{27}$

Trough $\mathrm{FEV}_{1}$ at week 12 was the primary outcome. Enrolled patients included males and females over 40 years of age, with a smoking history of $\geq 10$ pack-years, a diagnosis of moderate to severe stable COPD, ${ }^{9}$ a post-bronchodilator $\mathrm{FEV}_{1} \geq 30 \%$ and $<80 \%$ of the predicted normal, and postbronchodilator $\mathrm{FEV}_{1} /$ forced vital capacity $<0.70$.

Other key secondary assessments included evaluation of dyspnea using the transition dyspnea index at week 26 and health status measurements derived from the total score on the St George's Respiratory Questionnaire at week 52. Additional evaluations included comparisons between open-label tiotropium 


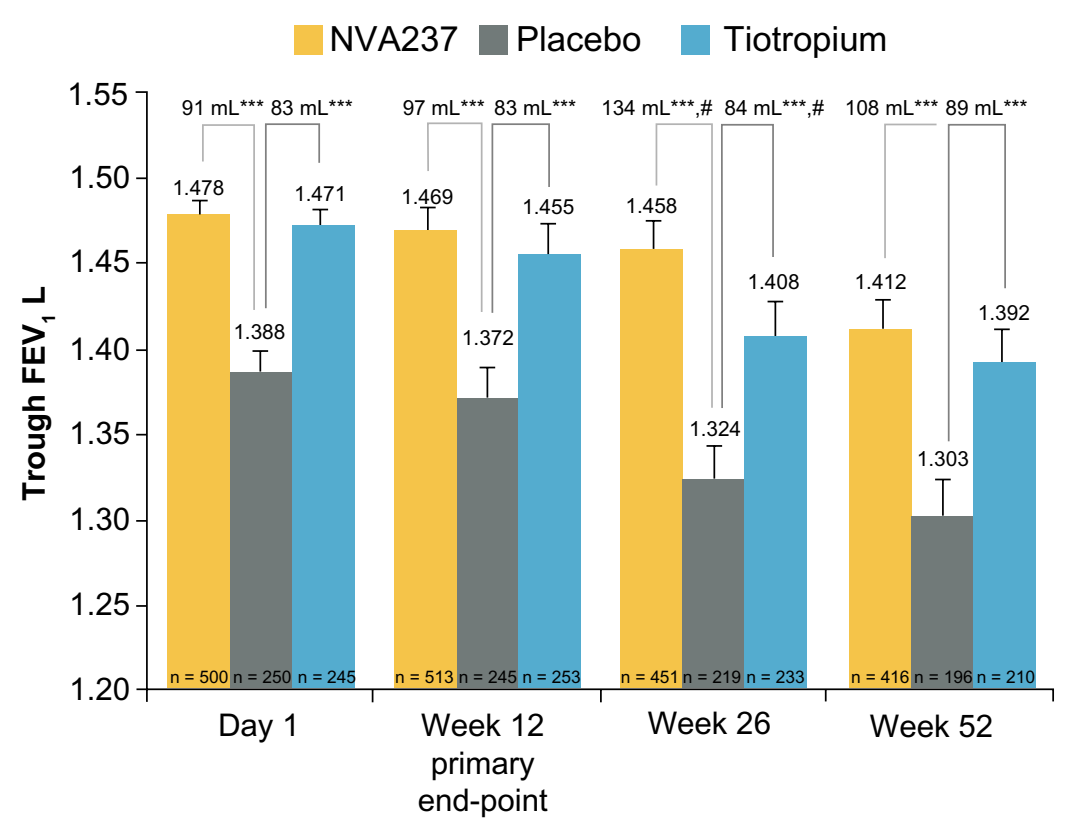

Figure 3 Trough forced expiratory volume in I s (FEV) at day I and weeks I2, 26 and 52.

Notes: Data presented as least squares mean \pm SE. ${ }^{* * * P}<0.00$ I versus placebo; ${ }^{*} P=0.007$ versus tiotropium. Reproduced from Kerwin E, Hebert J, Gallagher N, et al. Efficacy and safety of NVA237 versus placebo and tiotropium in patients with COPD: the GLOW2 study. Eur Respir J. 2012;40:1 I06-1। I4. ${ }^{28}$

$18 \mathrm{mg}$, placebo, and NVA237 in relation to all the study endpoints. GLOW 2 was not adequately powered to demonstrate statistical superiority of NVA237 versus tiotropium.

\section{Efficacy data}

Of the 1066 patients randomized, 810 completed the study according to protocol requirements. Treatment with
NVA237 resulted in a significant improvement in trough $\mathrm{FEV}_{1}$, which showed a mean increase of $97 \mathrm{~mL}(95 \%$ confidence interval [CI] 64.6-130.2; $P<0.001)$ at week 12. The trough $\mathrm{FEV}_{1}$ at week 12 in the tiotropium group showed a mean improvement of $83 \mathrm{~mL}$ (95\% CI 45.6-121.4; $P<0.001$, Figure 3 ). As early as the first dose on day 1 , patients receiving NVA237 showed rapid improvement in

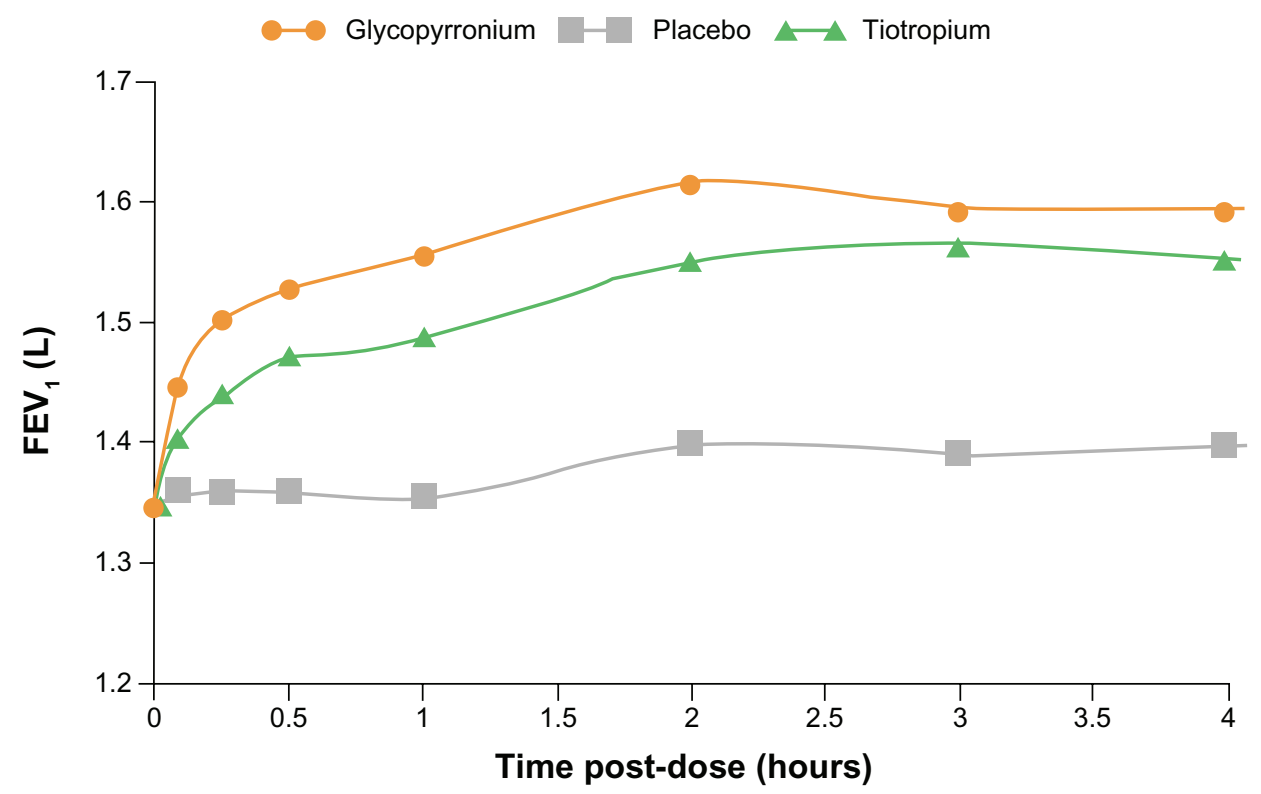

Figure $4 \mathrm{FEV}$, at each time point up to 4 hours post-dose on day I in GLOW2.

Notes: Data are LSM: $P<0.001$ for glycopyrronium and tiotropium versus placebo at all time points from 5 minutes to 4 hours: $P<0.01$ for glycopyrronium versus tiotropium at all time points from 5 minutes to 4 hours. Reproduced from Kerwin E, Hebert J, Gallagher N, et al. Efficacy and safety of NVA237 versus placebo and tiotropium in patients with COPD: the GLOW2 study. Eur Respir J. 20 I2;40: I I06-1 I I4. ${ }^{28}$

Abbreviations: $\mathrm{FEV}_{1}$, forced expiratory volume in one second; GLOW, Glycopyrronium bromide in COPD airways; LSM, least squares means. 
$\mathrm{FEV}_{1}$ compared with placebo. During the time interval from five minutes to four hours post-dosing, NVA237 was associated with significantly greater improvements in $\mathrm{FEV}_{1}$ compared with both placebo $(P<0.001)$ and tiotropium $(P<0.01$, Figure 4$)$. With the exception of one predose measurement at -20 minutes at week $52(P<0.053)$, improvements in inspiratory capacity were significantly greater $(P<0.001)$ in patients receiving NVA237 and similar to improvements observed in the tiotropium group at almost all evaluated time points on day 1 and weeks 12 and $52 .{ }^{28}$ Among patients receiving NVA237 and tiotropium, trough forced vital capacity was significantly greater compared with placebo at day 1 and at weeks 12 , 26 , and $52(P<0.001)$. Both NVA237 and tiotropium were associated with comparable numeric differences compared with placebo for all outcomes.

\section{Dyspnea and quality of life data}

At week 26, the focal score for the transition dyspnea index improved with NVA237 compared with placebo
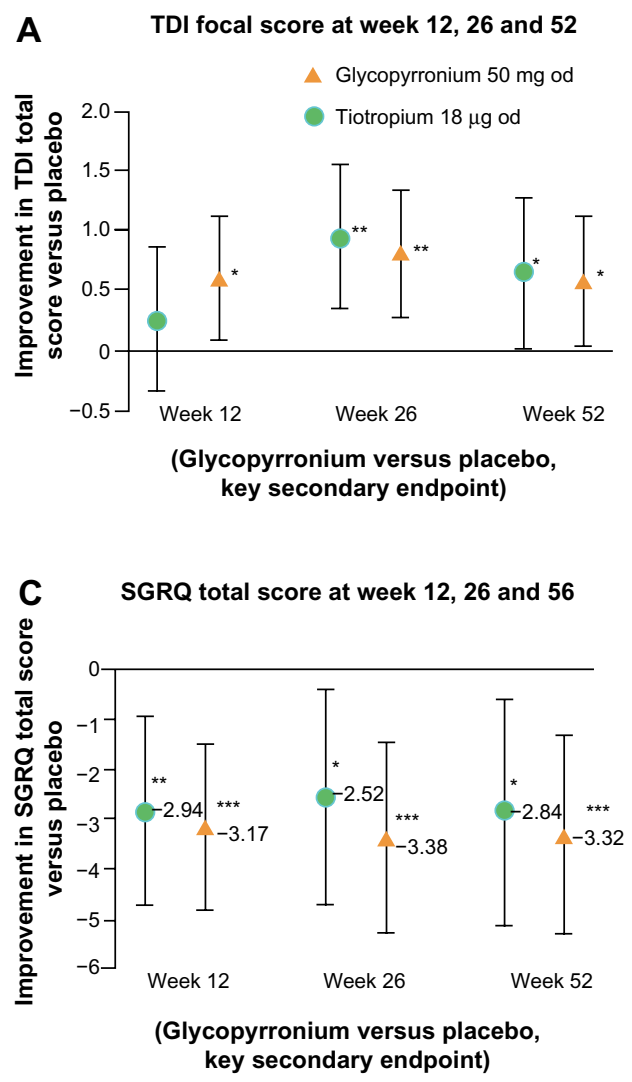

(2.13 versus 1.32 , with a least squares mean treatment difference of 0.88 [95\% CI 0.299-1.320]; $P<0.002$ ). This change was comparable with the improvement observed in the tiotropium group versus the placebo group (with a least squares mean treatment difference of 0.95 [95\% CI 0.356-1.521]; $P=0.002$, Figure 5). The St George's Respiratory Questionnaire total score improved significantly at 52 weeks with NVA237 and tiotropium compared with placebo (with a least squares mean treatment difference versus placebo of -3.32 [95\% CI -5.287 to -1.346$] ; P<0.001)$ and -2.84 [95\% CI -5.105 to -0.571$] ; P=0.014$, respectively, Figure 5.

\section{Exacerbation data}

The risk of moderate to severe COPD exacerbations was reduced by $34 \%$ during treatment with NVA237 $(P<0.001)$ compared with placebo. Patients receiving treatment with NVA237 also required less rescue medication $(P<0.039$ versus placebo, Figure 6).
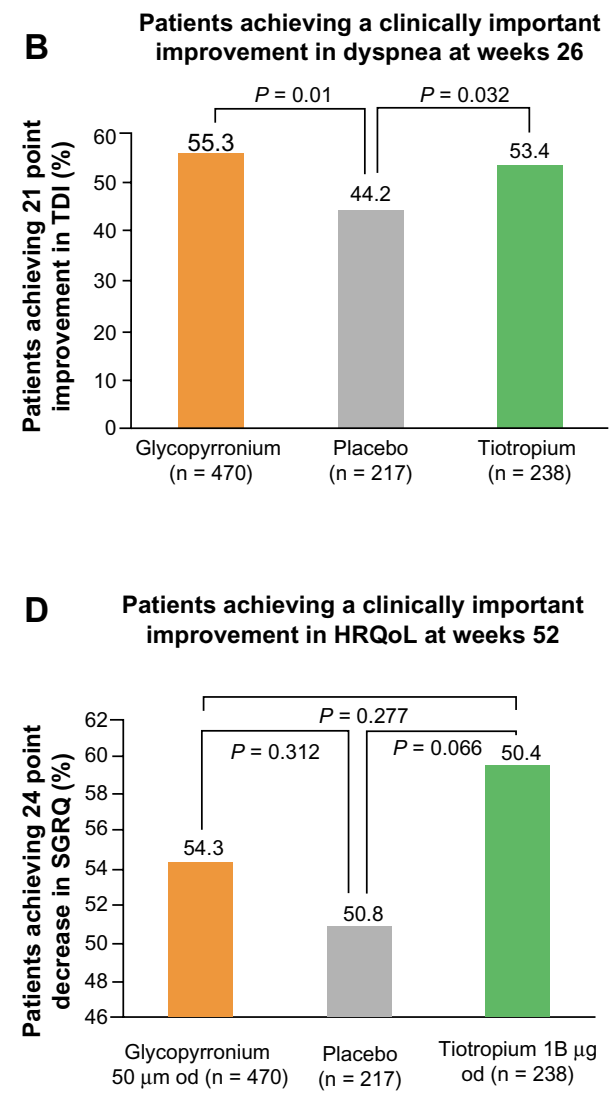

Figure 5 Improvements in (A and B) dyspnea and (C and $\mathbf{D})$ health-related quality of life with glycopyrronium versus placebo in GLOW2.

Notes: Data are LSM $\pm 95 \% \mathrm{Cl}$. $* P<0.05$; $* * P<0.0$ I; $* * * P<0.00$ I versus placebo. Reproduced with permission: Buhl R, Banjeri D. Profile of glycopyrronium for once-daily treatment of moderate-to-severe COPD. Int J Chron Obstruct Pulmon Dis. 20I2;7:729-74I."'

Abbreviations: HRQoL, health-related quality of life; GLOW, GLycopyrronium bromide in COPD airways; LSM, Least squares means; Cl, Confidence interval; TDI, Transition Dyspnea Index; od, once daily; OR, odds ratio; SGRQ, St George's Respiratory Questionnaire. 


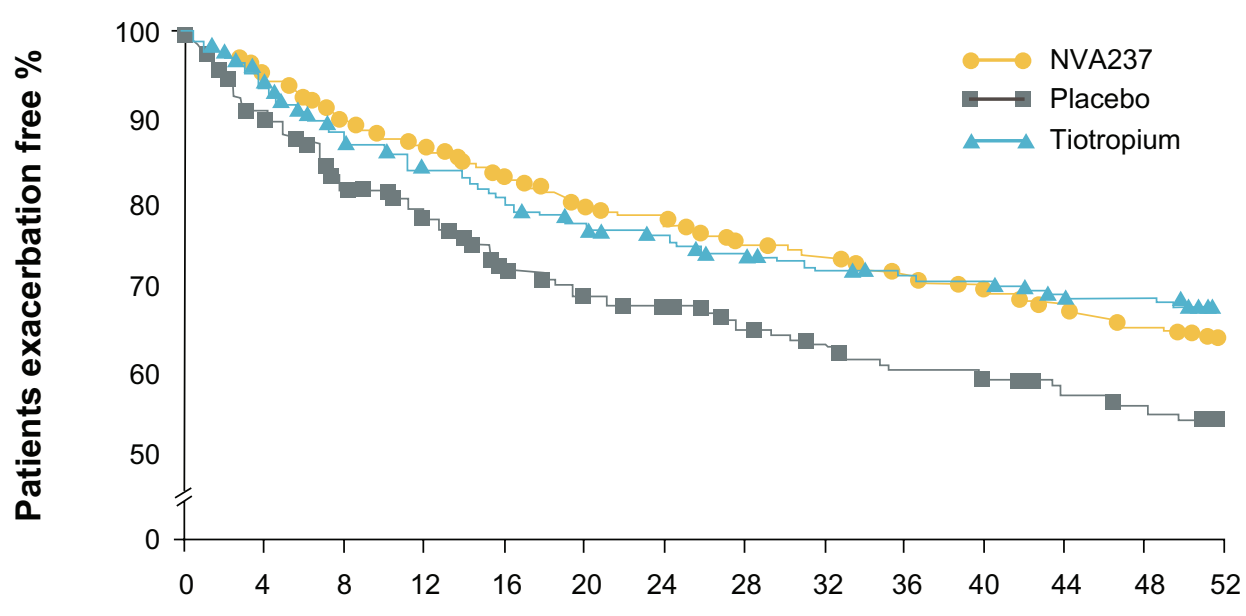

Time in weeks to first exacerbation

Number at risk

$\begin{array}{lrlllllllllllr}\text { NVA237 } & 495 & 451 & 426 & 394 & 370 & 360 & 341 & 335 & 318 & 310 & 296 & 282 & 239 \\ \text { Placebo } & 229 & 202 & 188 & 168 & 159 & 153 & 142 & 137 & 129 & 129 & 122 & 116 & 98 \\ \text { Tiotropium } & 245 & 222 & 209 & 200 & 190 & 184 & 176 & 169 & 166 & 163 & 157 & 155 & 129\end{array}$

Figure 6 Kaplan-Meier plot of the time to first moderate or severe chronic obstructive pulmonary disease exacerbation.

Note: Reproduced from Kerwin E, Hebert J, Gallagher N, et al. Efficacy and safety of NVA237 versus placebo and tiotropium in patients with COPD: the GLOW2 study. Eur RespirJ. 2012;40:1106-1114.28

\section{Safety data}

There were no apparent differences in safety profiles across the treatment groups. Pooled data related to adverse events in GLOW 1 and GLOW 2 are shown in Table 2 .

\section{Summary}

GLOW 2 demonstrated that NVA237 $50 \mathrm{mg}$ once daily provided significant improvements in lung function, dyspnea, health status, exacerbations, and use of rescue medication in comparison with placebo, and was comparable with tiotro-

Table 2 Most frequent adverse events ( $\geq 5 \%$ in any treatment group); SAEs occurring in $\geq 5$ patients in any treatment group, deaths, discontinuations due to adverse events and electrocardiographic abnormalities; pooled data from GLOWI and GLOW2

\begin{tabular}{|c|c|c|c|}
\hline & $\begin{array}{l}\text { Glycopyrronium } 50 \mu \mathrm{g} \text { od } \\
(\mathrm{n}=1075)\end{array}$ & $\begin{array}{l}\text { Placebo } \\
(n=535)\end{array}$ & $\begin{array}{l}\text { Tiotropium } 18 \mu \mathrm{g} \text { od } \\
(\mathrm{n}=267)\end{array}$ \\
\hline Patients with adverse events, $\mathrm{n}(\%)$ & $719(66.8)$ & $379(70.8)$ & $198(74.2)$ \\
\hline COPD worsening & $302(28.1)$ & $123(23.0)$ & $90(33.7)$ \\
\hline Upper respiratory tract infection & $80(7.4)$ & $53(9.9)$ & $30(1 \mathrm{I} .2)$ \\
\hline Nasopharyngitis & $75(7.0)$ & $36(6.7)$ & $21(7.9)$ \\
\hline Patients with SAEs, n (\%) & $112(10.4)^{\mathrm{a}}$ & $67(12.5)$ & $4 \mathrm{I}(15.4)^{\mathrm{a}}$ \\
\hline COPD worsening & $19(3.6)$ & $16(6.0)$ & $13(4.9)$ \\
\hline Pneumonia & $7(1.3)$ & $7(2.6)$ & $4(1.5)$ \\
\hline Atrial fibrillation & $7(0.7)$ & 0 & 0 \\
\hline Upper respiratory tract infection, bacterial & $5(0.5)$ & $5(0.9)$ & $2(0.7)$ \\
\hline Deaths, n (\%) & $3(0.6)^{b}$ & $2(0.7)$ & $2(0.7)$ \\
\hline Discontinuation due to adverse event(s) & $42(8.0)$ & $31(11.6)$ & $20(7.5)$ \\
\hline \multicolumn{4}{|l|}{ Electrocardiographic abnormalities } \\
\hline Total notable & $45(4.2)$ & $19(3.6)$ & $14(5.3)$ \\
\hline $\mathrm{QTcF}>500 \mathrm{msec}$ & $2(0.2)$ & $2(0.4)$ & 0 \\
\hline Increase from baseline $30-60 \mathrm{msec}$ & $142(13.2)$ & $60(11.2)$ & $43(16.2)$ \\
\hline Increase from baseline $>60 \mathrm{msec}$ & $7(0.6)$ & $2(0.4)$ & 0 \\
\hline
\end{tabular}

Notes: alncludes patients that had events that occurred during the 30-day follow-up period; bincludes two patients who died during the 30-day follow-up period. Adapted from D'Urzo A, Ferguson GT, van Noord JA, et al. Efficacy and safety of once-daily NVA237 in patients with moderate-to-severe COPD: the GLOWI trial. Respir Res. 201 I;12:156 and Kerwin E, Hebert J, Gallagher N, et al. Efficacy and safety of NVA237 versus placebo and tiotropium in patients with COPD: the GLOW2 study. Eur Respir J. 2012;40:1106-1114.27.28

Abbreviations: SAEs, serious adverse events; GLOW, Glycopyrronium bromide in COPD airways; od, once-daily; COPD, chronic obstructive pulmonary disease; QTcF, QT interval with Fridericia's correction; msec, milliseconds. 
pium. The results of GLOW 2 suggest that NVA237 has features related to both efficacy and safety that will allow clinicians to consider it as an alternative LAMA for management of COPD.

\section{GLOW 3}

\section{Study design and methods}

In the multicenter GLOW 3 (GLycopyrronium bromide in COPD airWays clinical study 3 ), patients were randomized into two treatment arms using a crossover design, with placebo followed by NVA237 $50 \mu \mathrm{g}$ once daily or NVA237 $50 \mu \mathrm{g}$ once daily followed by placebo for three weeks, with a 14-day washout interval. ${ }^{29}$ Men and women with moderate to severe COPD were eligible for enrollment in GLOW 3 if they were aged $\geq 40$ years, had a smoking history of $\geq 10$ pack-years, an $\mathrm{FEV}_{1}<80 \%$ and $\geq 40 \%$ of predicted normal, and $\mathrm{FEV}_{1}$ /forced vital capacity $<70 \%$. The definition of diagnostic criteria for COPD was similar to that described in GLOW $1^{27}$ and GLOW $2 .{ }^{28}$

The primary outcome measure was the effect of NVA237 $50 \mu \mathrm{g}$ on exercise tolerance compared with placebo after three weeks of treatment on day 21. One hour after drug administration on days 1 and 21, exercise tolerance was measured by exercise endurance time during a submaximal cycle ergometry test. Submaximal exercise testing was performed according to recognized standards. Exercise endurance was defined as the time from commencement of loaded pedaling to cessation of exercise..$^{30}$ An important key secondary measurement included inspiratory capacity, derived spirometrically, at isotime, ie, the last time point in the submaximal constant-load cycle ergometry test at which the patient had a valid test result for both treatment periods.

Table 3 IC at rest (prior to exercise) and peak exercise on Days I and 21

\begin{tabular}{|c|c|c|c|}
\hline & $\begin{array}{l}\text { NVA237 } \\
\text { (LSM, 95\% CI) }\end{array}$ & $\begin{array}{l}\text { Placebo } \\
\text { (LSM, 95\% CI) }\end{array}$ & $\begin{array}{l}\text { NVA237-Placebo } \\
\text { (LSM difference, } \\
95 \% \mathrm{Cl} \text { ) }\end{array}$ \\
\hline \multicolumn{4}{|c|}{ IC at peak exercise, $L$} \\
\hline Day I & $2.23(2.18,2.29)$ & $2.02(1.96,2.07)$ & $0.22(0.16,0.27)$ \\
\hline Day 21 & $2.22(2.16,2.28)$ & $2.03(1.97,2.10)$ & $0.19(0.12,0.25)$ \\
\hline \multicolumn{4}{|c|}{ IC at rest (Bodybox)*, L } \\
\hline Day I & $2.53(2.46,26 I)$ & $2.24(2.16,2.32)$ & $0.29(0.19,0.40)$ \\
\hline Day 21 & $2.49(2.40,2.59)$ & $2.26(2.17,235)$ & $0.23(0.14,0.33)$ \\
\hline \multicolumn{4}{|c|}{ IC at rest (Spirometry), $\mathrm{L}$} \\
\hline Day I & $2.44(2.38,2.50)$ & $2.18(2.12,2.24)$ & $0.26(0.18,0.33)$ \\
\hline Day 21 & $2.39(2.33,2.45)$ & $2.17(2.10,2.23)$ & $0.22(0.15,0.30)$ \\
\hline
\end{tabular}

Notes: *Whole body plethysmography. Copyright $\odot$ 2012, Dovepress. Reproduced with permission from Beeh MK, Singh D, Di Scala L, Drollmann A. Once-daily NVA237 improves exercise tolerance from the first dose in patients with COPD: the GLOW3 trial. Int J Chron Obstruct Pulmon Dis. 201 2;7: 503-513. ${ }^{29}$

Abbreviations: $\mathrm{Cl}$, confidence interval; IC, inspiratory capacity; LSM, least square mean.

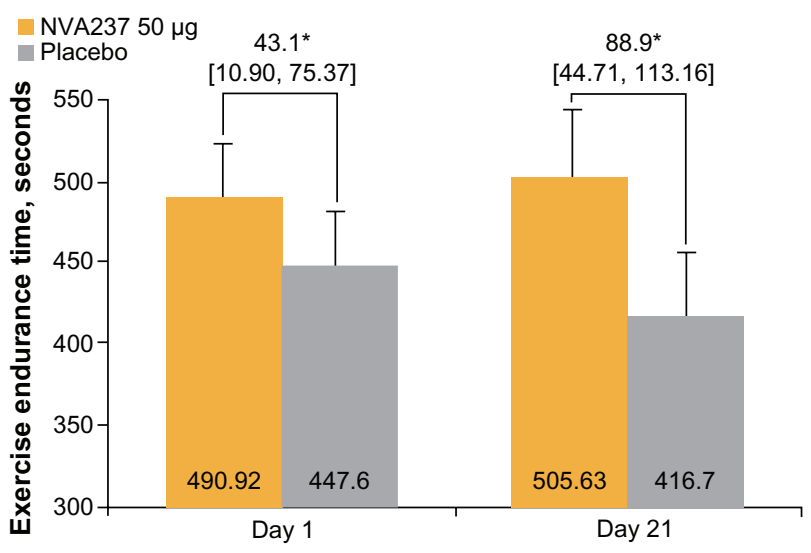

Figure 7 Exercise endurance time on Days I and 21.

Notes: Values are LSM [95\% Cl]. $* P<0.001$. Copyright (c) 2012, Dovepress. Reproduced with permission from Beeh MK, Singh D, Di Scala L, Drollmann A. Once-daily NVA237 improves exercise tolerance from the first dose in patients with COPD: the GLOW3 trial. Int J Chron Obstruct Pulmon Dis. 2012;7: 503-5I3. ${ }^{29}$ Abbreviation: LSM, least square mean.

\section{Efficacy data}

Ninety-five (88\%) of 108 randomized patients completed the study. More than $96 \%$ of the patients completed periods 1 and 2 . Their mean age was 60.5 years ( $58 \%$ male), with the majority being Caucasian (96\%). During the incremental work test, the mean $\mathrm{W}_{\max }$ at screening was $87.8 \pm 28.8 \mathrm{~W}$, while the submaximal workload averaged $70.2 \pm 23.1 \mathrm{~W}$.

Both at rest and at peak exercise, inspiratory capacity was consistently higher in the NVA237 group compared with the placebo group on days 1 and $21(P<0.05$, Table 3$)$. NVA237 also produced a statistically significant treatment difference in inspiratory capacity at isotime on day 1 versus placebo $(P<0.001)$ and on day 21 versus placebo $(P<0.001)$.

After three weeks of treatment with NVA237, exercise endurance time was significantly superior compared with placebo. The least squares mean treatment difference on day 21 between the NVA237 and placebo groups was 88.9 seconds, a change that corresponded to an approximately $21 \%$ betweengroup difference $(P<0.001$, Figure 7$)$. Data obtained on day 1 revealed a least squares mean treatment difference of 43.1 seconds between the groups, a change that corresponded to an approximately $10 \%$ between-group difference $(P<0.001)$.

\section{Safety data}

The overall proportion of patients who experienced at least one adverse event was comparable between those receiving NVA237 and those receiving placebo. Most adverse events were considered mild or moderate in severity and were not considered to be related to the study medication. The number of patients who discontinued study participation due to adverse events was low, whether treated with NVA237 or placebo. No 
deaths were reported during the study. The only serious studyrelated adverse event reported was a herniated disc diagnosed in a patient receiving NVA237; this was not considered to be drug-related. There were no unexpected changes in vital signs, electrocardiograms, and hematology or biochemistry parameters during the study.

\section{Summary of GLOW I, 2, and 3}

Based on the data highlighted in the Phase III studies described above, NVA237 should become an important addition to the armamentarium for COPD management. Improvements in trough $\mathrm{FEV}_{1}$ with NVA237 compared with both placebo and tiotropium were clinically relevant and appeared to be sustained over time. Changes in inspiratory capacity were significantly greater than in the placebo group and comparable with tiotropium, suggesting that NVA237 will have a very positive impact on minimizing the deleterious influence of both static and dynamic hyperinflation on COPD-related outcomes. It is also evident that NVA237 has a beneficial influence on dyspnea, quality of life, and exercise tolerance, and that it is associated with a significant reduction in COPD-related exacerbations among patients with moderate to severe disease.

\section{Evolving role of NVA237 in COPD Combination therapy with long-acting bronchodilators}

There is a growing focus on promoting a strategy of maximal bronchodilation in patients with COPD, particularly among those individuals with persistent symptoms and disability. ${ }^{1}$ Depending on the stage of disease, a single bronchodilator may not be adequate for many individuals. At the present time, there is a lack of clarity around when to initiate therapy with a combination of drugs from different classes. Combining bronchodilators of different pharmacologic classes has been shown to be superior to the individual components and associated with a reduction in the risk of side effects compared with increasing the dose of a single bronchodilator. ${ }^{1}$ Evidence describing combinations of longacting bronchodilators (LAMAs/LABAs) suggest that these preparations may be effective in the management of COPD, given their positive influence on optimizing symptom control, their potential to improve patient compliance, and their ability to simplify disease management.

Addition of a second long-acting bronchodilator to therapy for patients in groups B-D is recommended in the revised Global Initiative for Chronic Obstructive Lung Disease 2011 guideline $^{1}$ as a strategy to optimize symptom control (Figure 1). Addition of ICS to LABAs/LAMAs combination therapy is recommended for patients at risk of experiencing COPD exacerbations in groups $\mathrm{C}$ or $\mathrm{D}$ (Figure 1). ${ }^{1}$ Interestingly, despite reports suggesting that ICS have limited efficacy in terms of modifying the long-term decline of $\mathrm{FEV}_{1}$ in $\mathrm{COPD},{ }^{31,33}$ these medications continue to be widely used in patients with COPD. ${ }^{1}$

LABAs and LAMAs appear to have a separate but complementary influence on bronchodilation. ${ }^{34}$ The primary effect of LABAs appears to be mediated by stimulation of $\beta_{2}$-adrenergic receptors located in airway smooth muscle. The antagonistic influence of LAMAs at the level of the muscarinic receptors in airway smooth muscle serves to block the signaling cascade that ultimately results in smooth muscle contraction. ${ }^{35}$

There is growing evidence that LAMA/LABA combinations are efficacious in terms of improving trough $\mathrm{FEV}_{1}$, dyspnea, quality of life, and use of rescue medication compared with these agents used alone. ${ }^{34,36-44}$ At the present time, there is a number of new LABA/LAMA combinations being studied in the management of COPD. ${ }^{45}$ Much of the evidence describing the benefits of this strategy centers around the free combination of the LAMA tiotropium with the LABAs, formoterol, salmeterol, and indacaterol. Several once-daily fixed-dose LABA/LAMA combinations are currently in development, and include QVA149 (indacaterol-glycopyrronium), vilanterol-umeclidinium, and olodaterol-tiotropium. ${ }^{45}$ The fixed-dose LABA/LAMA combination furthest in development is indacaterolglycopyrronium (QVA149).

\section{QVAI49}

In a double-blind, four-period, crossover Phase II study, 154 patients with moderate to severe COPD were randomized to receive QVA149 (indacaterol $300 \mu \mathrm{g}+\mathrm{NVA} 23750 \mu \mathrm{g}$ ), indacaterol $300 \mu \mathrm{g}$, indacaterol $600 \mu \mathrm{g}$, or placebo for seven days followed by a seven-day washout period between each treatment. ${ }^{46}$ Compared with placebo and indacaterol, QVA149 significantly increased trough $\mathrm{FEV}_{1}$ on days 1 and 7 (primary endpoint). QVA149 also had a rapid onset of action at five minutes post-dose on day 1, and was associated with sustained bronchodilation over a 24-hour period. Further, improvement in $\mathrm{FEV}_{1}$ at all the post-baseline time points on day 1 were significantly greater with QVA149 than with indacaterol or placebo $(P<0.05)$. Compared with placebo and indacaterol, trough forced vital capacity and peak $\mathrm{FEV}_{1}$ on days 1 and 7 were also significantly greater for QVA149 $(P<0.05)$. Overall, all treatments were well tolerated. Recent results 
from Phase III studies ${ }^{47,48}$ show that QVA149 provides significant and sustained improvement in lung function compared with placebo, tiotropium, salmeterol-fluticasone, and the separate components, indacaterol and NVA237 (ILLUMINATE and SHINE studies, respectively), over 26 weeks, with significant symptomatic benefits also reported. It is relevant to note that the SHINE study enrolled more than 2100 patients and met the primary endpoint by demonstrating the superiority in trough $\mathrm{FEV}_{1}$ $(P<0.001)$ achieved by once-daily QVA149 compared with once-daily indacaterol or once-daily NVA237 in patients with moderate to severe COPD. ${ }^{47}$ Taken together, the emerging data indicate that NVA237 is efficacious both as monotherapy and in combination with indacaterol. The choice between monotherapy versus a LABA/LAMA combination as initial maintenance therapy will be driven by the expectation of achieving maximal bronchodilation and superior clinical outcomes compared with single use of either a LABA or LAMA in patients with persistent and disabling symptoms. As more data on LABA/LAMA combination therapy become available, it is very likely that this approach will be the most appropriate one for achieving optimal outcomes in patients with established COPD.

\section{Delivery of NVA237via Breezhaler device}

The Breezhaler has been shown to be a user-friendly device, and is a single-dose dry-powder inhaler suitable for use by patients with COPD of all ages with a wide range of disease severity. ${ }^{49,50}$ Irrespective of the degree of pulmonary impairment and patient age, studies with the Breezhaler have shown that it delivers a consistent dose of drug, with no reported device failures. Further, the Breezhaler has lower internal resistance properties compared with the HandiHaler used to deliver tiotropium (specific airflow resistances of 2.2 and $5.1 \times 10^{-2} \mathrm{kPa}_{1 / 2}$ $\mathrm{L}^{-1}$ minute, respectively). ${ }^{49}$ The specific airflow resistance properties of the Diskus ${ }^{\circledR}$ and Turbuhaler ${ }^{\circledR}$ are $2.1 \times 10^{-2}$ $\mathrm{kPa}_{1 / 2} \mathrm{~L}^{-1}$ minute and $3.2 \times 10^{-2} \mathrm{kPa}_{1 / 2} \mathrm{~L}^{-1}$ minute, respectively. ${ }^{51}$ An inhaler's internal resistance will determine the effort patients have to make to achieve adequate inspiratory flows for effective and reproducible dose delivery. ${ }^{52,53}$ Therefore, low-resistance devices would tend to require less patient effort in order to generate adequate inspiratory flows compared with high-resistance devices, making them more suitable for older patients and for those with severe COPD, who may experience difficulties in generating adequate flows.

\section{Conclusion}

Bronchodilator therapy is a central strategy in the management of symptomatic COPD, and the agents that are currently available have been shown to have very positive effects on many important clinical outcomes. NVA237 (glycopyrronium bromide), the newest LAMA to receive approval for management of COPD, appears to have a clinically and statistically meaningful impact on many relevant management parameters described in the pivotal studies, ie, GLOW $1,{ }^{27}$ GLOW $2,{ }^{28}$ and GLOW $3 .{ }^{29}$ The inhaled route will continue to be the preferred route of administration in order to minimize systemic effects. Not uncommonly, the complex procedures involved in use of the inhaler devices to deliver medication and frequent dosing are the main barriers to compliance among patients with COPD.

A number of recent advances in the treatment of COPD have the potential to make management of the disease more convenient for patients, particularly for those who need LABA/LAMA combination therapy, and provide long-term, day-to-day control of their symptoms. Research aimed at developing LAMAs with efficacy and safety equivalent to tiotropium, such as NVA237, provides alternatives for patients with COPD. The development of LABAs with a 24-hour duration of action has also permitted the development of LABA/LAMA combinations for oncedaily administration in a single inhaler. Many of these combinations have been shown to be efficacious in terms of significantly improving lung function and other outcomes compared with monotherapy, with either equivalent or fewer side effects. Further research should focus on examining the long-term efficacy and safety of different bronchodilator combinations, especially their ability to improve patientrelevant outcomes, and their impact on the natural history of COPD when introduced early in the disease process.

\section{Disclosure}

The author has received research, consulting, and lecturing fees from GlaxoSmithKline, Sepracor, Schering Plough, Altana, Methapharma, AstraZeneca, ONO Pharma, Merck Canada, Forest Laboratories, Novartis Canada/ US, Boehringer Ingelheim (Canada) Ltd, Pfizer Canada, SkyePharma, and KOS Pharmaceuticals.

\section{References}

1. Global Initiative for Obstructive Lung Disease (GOLD). Global strategy for the diagnosis, management and prevention of chronic obstructive pulmonary disease. 2011. Available from: http://www.goldcopd.org/ guidelines-gold-summary-2011.html.

2. Viegi G, Pistelli F, Sherrill DL, Maio S, Baldacci S, Carrozzi L. Definition, epidemiology and natural history of COPD. Eur Respir J. 2007;30:993-1013. 
3. UK Medicines Information New Drugs Online. Glycopyrrolate; 2012. Available from: http://www.ukmi.nhs.uk/applications/ndo/ record_view_open.asp?newDrugID=4793. Accessed April 12, 2013.

4. UK Medicines Information New Drugs Online. Aclidinium bromide; 2012. Available from: http://www.ukmi.nhs.uk/applications/ndo/ record_view_open.asp?newDrugID=4515. Accessed April 12, 2012.

5. Tashkin DP. Long-acting anticholinergic use in chronic obstructive pulmonary disease: efficacy and safety. Curr Opin Pulm Med. 2010;16: 97-105.

6. Sykes DA, Dowling MR, Charlton SJ. Exploring the mechanism of agonist efficacy: a relationship between efficacy and agonist dissociation rate at the muscarinic M3 receptor. Mol Pharmacol. 2009;76: 543-551.

7. Vogelmeier C, Banerji D. NVA237, a long-acting muscarinic antagonist, as an emerging therapy for chronic obstructive pulmonary disease. Ther Adv Respir Dis. 2011;5:163-173.

8. Sechaud R, Ranard D, Zhang-Auberson L, de la Motte S, Drollmann A, Kaiser G. Pharmacokinetics of multiple inhaled NVA237 doses in patients with chronic obstructive pulmonary disease (COPD). Int $J$ Clin Pharmacol Ther. 2012;50:118-128.

9. Global Initiative for Chronic Obstructive Lung Disease (GOLD 2008). Global Strategy for the Diagnosis, Management and Prevention of Chronic Obstructive Pulmonary Disease. Available from: http://www. ncbi.nlm.nih.gov/pubmed/17507545.

10. National Institute for Health and Clinical Excellence. Chronic obstructive pulmonary disease: management of chronic obstructive pulmonary disease in adults in primary and secondary care. London, UK: National Clinical Guideline Centre; 2010. Available from: http:/guidance.nice. org.uk/CG101/Guidance/pdf/English. Accessed April 13, 2013.

11. Buhl R, Banjeri D. Profile of glycopyrronium for once-daily treatment of moderate-to-severe COPD. Int J Chron Obstruct Pulmon Dis. 2012;7:729-741.

12. Vogelmeier C, Hederer B, Glaab T, et al. Tiotropium versus salmeterol for the prevention of exacerbations of COPD. $N$ Engl J Med. 2011;364:1093-1103.

13. Calverley PM, Anderson JA, Celli B, et al. Salmeterol and fluticasone propionate and survival in chronic obstructive pulmonary disease. N Engl J Med. 2007;356:775-789.

14. Tashkin DP, Celli B, Senn S, et al. A 4-year trial of tiotropium in chronic obstructive pulmonary disease. N Engl J Med. 2008;359: 1543-1554.

15. Wedzicha JA, Calverley PM, Seemungal TA, et al. The prevention of chronic obstructive pulmonary disease exacerbations by salmeterol/ fluticasone propionate or tiotropium bromide. Am J Respir Crit Care Med. 2008;177:19-26.

16. Aaron SD, Vandehmheen KL, Fergusson D, et al. Tiotropium in combination with placebo, salmeterol, or fluticasone-salmeterol for treatment of chronic obstructive pulmonary disease. Ann Intern Med. 2007; 146:545-555.

17. Casaburi R, Mahler DA, Jones PW, et al. A long-term evaluation of once-daily inhaled tiotropium in chronic obstructive pulmonary disease. Eur Respir J. 2002;19:217-224.

18. O'Donnell DE, Fluge T, Gerken F, et al. Effects of tiotropium on lung hyperinflation, dyspnoea and exercise tolerance in COPD. Eur Respir J. 2004;23:832-840

19. Celli B, Zuwallack R, Wang S, Kesten S. Improvement in resting inspiratory capacity and hyperinflation with tiotropium in COPD patients with increased static lung volumes. Chest. 2003;124:1743-1748.

20. Casaburi R. Factors determining constant work rate exercise tolerance in COPD and their role in dictating the minimal clinically important difference in response to interventions. COPD. 2005;2:131-136.

21. Maltais F, Hamilton A, Marciniuk D, et al. Improvements in symptomlimited exercise performance over $8 \mathrm{~h}$ with once-daily tiotropium in patients with COPD. Chest. 2005;128:1168-1178.

22. Donohue JF, van Noord JA, Bateman ED, et al. A 6-month, placebocontrolled study comparing lung function and health status changes in COPD patients treated with tiotropium or salmeterol. Chest. 2002;122: $47-55$.
23. Niewoehner DE, Rice K, Cote C, et al. Prevention of exacerbations of chronic obstructive pulmonary disease with tiotropium, a once-daily inhaled anticholinergic bronchodilator: a randomized trial. Ann Intern Med. 2005;143:317-326.

24. Fogarty C, Hattersley H, Di Scala L, Drollmann A. Bronchodilatory effects of NVA237, a once daily long-acting muscarinic antagonist, in COPD patients. Respir Med. 2011;105:337-342.

25. Verkindre C, Fukuchi Y, Flemale A, et al. Sustained 24-h efficacy of NVA237, a once-daily long-acting muscarinic antagonist, in COPD patients. Respir Med. 2010;104:1482-1489.

26. Vogelmeier C, Verkindre C, Cheung D, et al. Safety and tolerability of NVA237, a once-daily long-acting muscarinic antagonist, in COPD patients. Pulm Pharmacol Ther. 2010;23:438-444.

27. D'Urzo A, Ferguson GT, van Noord JA, et al. Efficacy and safety of once-daily NVA237 in patients with moderate-to-severe COPD: the GLOW1 trial. Respir Res. 2011;12:156.

28. Kerwin E, Hebert J, Gallagher N, et al. Efficacy and safety of NVA237 versus placebo and tiotropium in patients with COPD: the GLOW2 study. Eur Respir J. 2012;40:1106-1114.

29. Beeh MK, Singh D, Di Scala L, Drollmann A. Once-daily NVA237 improves exercise tolerance from the first dose in patients with COPD: the GLOW3 trial. Int J Chron Obstruct Pulmon Dis. 2012;7: 503-513.

30. European Respiratory Society. Clinical exercise testing with reference to lung diseases: indications, standardization and interpretation strategies. ERS Task Force on Standardization of Clinical Exercise Testing. Eur Respir J. 1997;10:2662-2689.

31. Global Initiative for Chronic Obstructive Lung Disease. Global Strategy for the Diagnosis, Management, and Prevention of Chronic Obstructive Pulmonary Disease. Updated 2010. Available from: http://www. goldcopd.org/Guidelines/guideline-2010-gold-report.html.

32. Tashkin D, Celli B, Decramer M, et al. Prescribing patterns according to COPD treatment guidelines in patients enrolled in a global clinical trial. Proc Am Thorac Soc. 2006;3:A111.

33. Karner C, Cates CJ. The effect of adding inhaled corticosteroids to tiotropium and long-acting beta(2)-agonists for chronic obstructive pulmonary disease. Cochrane Database Syst Rev. 2011;9:CD009039.

34. Cazzola M, Molimard M. The scientific rationale for combining longacting beta2-agonists and muscarinic antagonists in COPD. Pulm Pharmacol Ther. 2010;23:257-267.

35. Roux E, Molimard M, Savineau JP, Marthan R. Muscarinic stimulation of airway smooth muscle cells. Gen Pharmacol. 1998;31:349-356.

36. van Noord JA, Aumann JL, Janssens E, et al. Comparison of tiotropium once daily, formoterol twice daily and both combined once daily in patients with COPD. Eur Respir J. 2005;26:214-222.

37. van Noord JA, Aumann JL, Janssens E, et al. Effects of tiotropium with and without formoterol on airflow obstruction and resting hyperinflation in patients with COPD. Chest. 2006;129:509-517.

38. van Noord JA, Aumann JL, Janssens E, et al. Combining tiotropium and salmeterol in COPD: effects on airflow obstruction and symptoms. Respir Med. 2010;104:995-1004.

39. Tashkin DP, Littner M, Andrews CP, Tomlinson L, Rinehart M, DenisMize K. Concomitant treatment with nebulized formoterol and tiotropium in subjects with COPD: a placebo-controlled trial. Respir Med. 2008;102:479-487.

40. Tashkin DP, Donohue JF, Mahler DA, et al. Effect of arformoterol twice daily, tiotropium once daily, and their combination in patients with COPD. Respir Med. 2009;103:516-524.

41. Maltais F, Beck E, Webster D, et al. Four weeks once daily treatment with tiotropium+olodaterol (BI 1744) fixed dose combination compared with tiotropium in COPD patients. Eur Respir J. 2010;36(S54): P5557.

42. Cazzola M, Di Marco F, Santus P, et al. The pharmacodynamic effects of single inhaled doses of formoterol, tiotropium and their combination in patients with COPD. Pulm Pharmacol Ther. 2004;17:35-39.

43. Vogelmeier C, Kardos P, Harari S, Gans SJ, Stenglein S, Thirlwell J. Formoterol mono- and combination therapy with tiotropium in patients with COPD: a 6-month study. Respir Med. 2008;102:1511-1520. 
44. Mahler DA, D’Urzo A, Bateman ED, et al. Concurrent use of indacaterol plus tiotropium in patients with COPD provides superior bronchodilation compared with tiotropium alone: a randomised, doubleblind comparison. Thorax. 2012;67:781-788.

45. D'Urzo A, Vogelmeier C. Future of chronic obstructive disease management. Expert Rev Respir Med. 2012;6:285-299.

46. van Noord JA, Buhl R, Laforce C, et al. QVA149 demonstrates superior bronchodilation compared with indacaterol or placebo in patients with chronic obstructive pulmonary disease. Thorax. 2010;65:1086-1091.

47. Bateman E, Ferguson GT, Barnes N, et al. Benefits of dual bronchodilation with QVA149 once daily versus placebo, indacaterol, NVA237 and tiotropium in patients with COPD: the SHINE study. Abstract presented at the European Respiratory Society Congress 2012, Vienna, Austria, September 1-5, 2012.

48. Vogelmeier C, Bateman E, Pallante J, et al. Once-daily QVA149 significantly improves lung function and symptoms compared to twice-daily fluticasone/salmeterol in COPD patients: the ILLUMINATE study. Abstract presented at the European Respiratory Society Congress, Vienna, Austria, September 1-5, 2012.
49. Chapman KR, Fogarty CM, Peckitt C, et al. Delivery characteristics and patients' handling of two single-dose dry-powder inhalers used in COPD. Int J Chron Obstruct Pulmon Dis. 2011;6:353-363.

50. Pavkov R, Mueller S, Fiebich K, et al. Characteristics of a capsule based dry powder inhaler for the delivery of indacaterol. Curr Med Res Opin. 2010;26:2527-2533.

51. Broeders ME, Molema J, Vermue NA, Folgering HT. Peak inspiratory flow rate and the slope of the inhalation profiles in dry powder inhalers. Eur Respir J. 2001;18:780-783.

52. Wieshammer S, Dreyhaupt J. Dry powder inhalers: which factors determine the frequency of handling errors? Respiration. 2008;75: $18-25$.

53. Terzano C. Dry powder inhalers and the risk of error. Respiration. 2008;75:14-15.
Therapeutics and Clinical Risk Management

\section{Publish your work in this journal}

Therapeutics and Clinical Risk Management is an international, peerreviewed journal of clinical therapeutics and risk management, focusing on concise rapid reporting of clinical studies in all therapeutic areas, outcomes, safety, and programs for the effective, safe, and sustained use of medicines. This journal is indexed on PubMed Central, CAS,

Submit your manuscript here: http://www.dovepress.com/therapeutics-and-clinical-risk-management-journal

\section{Dovepress}

EMBase, Scopus and the Elsevier Bibliographic databases. The manuscript management system is completely online and includes a very quick and fair peer-review system, which is all easy to use. Visit http://www.dovepress.com/testimonials.php to read real quotes from published authors. 